\title{
PENGARUH JUS KACANG PANJANG (VIGNA SINENSIS L.) TERHADAP KADAR GLUKOSA DARAH PADA PENDERITA DIABETES MELLITUS (DM) TIPE 2
}

\author{
Linda Widyarani \\ Departemen Keperawatan Gawat Darurat dan Manajemen Bencana, \\ Akademi Keperawatan Notokusumo Yogyakarta, Jl. Bener No. 26 Tegalrejo Yogyakarta \\ lindawidyarani@gmail.com
}

\begin{abstract}
ABSTRAK
Diabetes Mellitus (DM) adalah kelainan metabolik yang ditandai dengan hiperglikemia akibat gangguan sekresi dan atau kerja insulin. Hiperglikemia yang terjadi dan tidak terkontrol baik, dapat menyebabkan kerusakan berbagai sistem tubuh. Salah satu pengendalian kadar gula darah dapat dilakukan melalui menjaga diet sehat dengan gizi seimbang. Kacang panjang mempunyai kandungan gizi yaitu thiamin yang berefek positif pada regulasi kadar glukosa darah. Penelitian ini bertujuan mengetahui pengaruh jus kacang panjang (vigna sinensis L.) terhadap kadar glukosa darah pada penderita Diabetes Mellitus (DM) Tipe 2. Metode penelitian adalah quasi eksperiment dengan one group prepost test design dan teknik purposive sampling, kadar Glukosa Darah Puasa (GDP) diobservasi sebelum dan sesudah diberikan jus kacang panjang selama 7 hari. Jumlah sampel pada penelitian ini adalah 21 orang. Hasil analisis paired t test menunjukkan nilai signifikan $\mathrm{p} 0,000(\mathrm{p}<0,005)$, diartikan bahwa terdapat perbedaan yang signifikan antara kadar GDP sebelum dan sesudah minum jus kacang panjang. Pemberian jus kacang panjang selama 7 hari berpengaruh secara signifikan menurunkan kadar GDP pada responden.
\end{abstract}

Kata kunci: Diabetes Mellitus Tipe 2, Kadar Glukosa Darah, Jus Kacang Panjang

\section{THE EFFECT OF CONSUMING STRING BEANS (VIGNA SINENSIS L.) JUICE ON BLOOD GLUCOSE LEVEL PATIENTS WITH DIABETES MELLITUS TYPE 2}

\begin{abstract}
Diabetes mellitus is a group of metabolic diseases characterized by hyperglycemia resulting from defects in insulin secretion, insulin action, or both. Uncontrolled hyperglycemia of diabetes is associated with long-term damage, dysfunction, and failure of various organs. The aim of this study was to investigate the effect of consuming string beans (vigna sinensis L.) juice on blood glucose level patients with Diabetes Mellitus Type 2. One way to control blood glucose level is to eat a healthful diet. String beans juice is a healthful diet, are a rich source of thiamine. This study employed a quasy-experimental, with one group pre-post test design, fasting blood glucose were assessed at before and after treatment. There were 21 sample selected using purposive sampling. Paired t test was performed for data analysis. There was a statistically significant difference in blood glucose level before and after guven string beans juice with $p=0,000$. Consuming string beans juice can be one of the efforts to reduce blood glucose level in patient with DM Type 2.
\end{abstract}

Keyword: Diabetes Mellitus Tipe 2, Blood Glucose Level, String Beans Juice 


\section{PENDAHULUAN}

Diabetes Mellitus (DM) adalah kelainan metabolik yang ditandai dengan hiperglikemia akibat gangguan sekresi dan atau kerja insulin (Huether \& McCance, 2017). Diabetes Mellitus (DM) dikategorikan dalam dua kelompok, yaitu a) Diabetes Mellitus (DM) Tipe 1, terjadi akibat penghancuran autoimun dari sel $\beta$ penghasil insulin di pulau Langerhans pada pankreas (defisiensi absolute), dan b) Diabetes Mellitus (DM) Tipe 2, merupakan dampak dari gangguan sekresi insulin dan resistansi terhadap kerja insulin yang sering kali disebabkan oleh obesitas (defisiensi relatif) (Bilous \& Donelly, 2014). Angka kejadian DM di Indonesia masih menunjukkan kecenderungan meningkat. Indonesia adalah negara peringkat keenam di dunia setelah Tiongkok, India, Amerika Serikat, Brazil dan Meksiko dengan prevalensi $\pm 10,3$ juta pada usia 20-79 tahun. Riset Kesehatan Dasar (Riskesdas) menunjukkan peningkatan angka prevalensi yang signifikan, yaitu dari $6,9 \%$ di tahun 2013 meningkat mencapai 8,5\% di tahun 2018, sehingga estimasi jumlah penderita di Indonesia mencapai lebih dari 16 juta orang (Depkes, 2018). Berdasarkan Survailans Terpadu Penyakit (STP), pada tahun 2017, DM Tipe 2 merupakan penyakit terbanyak keempat di D.I.Yogyakarta dengan jumlah 8.321 kasus (Depkes, 2017).

DM dikarakteristikkan sebagai gangguan metabolik berupa hiperglikemia (glukosa darah puasa $\geq 126 \mathrm{mg} / \mathrm{dL}$ dan glukosa darah sewaktu $\geq 200 \mathrm{mg} / \mathrm{dL}$ ), disebabkan karena kelainan sekresi insulin, kerja insulin atau keduanya (Depkes, 2014). Hiperglikemia yang terjadi dan tidak terkontrol baik, dapat menyebabkan kerusakan berbagai sistem tubuh, kerusakan yang tersering menyerang saraf dan pembuluh darah. Hiperglikemia yang tidak ditangani dengan baik, menyebabkan berbagai komplikasi, antara lain: a) meningkatnya risiko penyakit jantung dan stroke, b) neuropati (kerusakan saraf) di kaki, yang meningkatkan kejadian ulkus kaki, infeksi, bahkan berakhir pada amputasi kaki, c) retinopati diabetikum, yang menyebabkan kebutaan akibat adanya kerusakan pembuluh darah kecil di retina, d) gagal ginjal, dan e) risiko kematian meningkat dua kali lipat dibandingkan pada bukan penderita DM (Depkes, 2014).

Pengendalian komplikasi DM yang baik, menjaga agar kadar gula darah berada pada rentang normal, dapat menurunkan komplikasi akibat DM. Pengendalian kadar gula darah dapat dilakukan melalui a) manajemen pengobatan yang tepat dan 
teratur, b) menjaga diet sehat dengan gizi seimbang, c) beraktivitas fisik yang aman, d) hindari rokok, alkohol dan zat karsinogenik lainnya (Depkes, 2014). Pengendalian kadar gula darah melalui mekanisme menjaga diet sehat dengan gizi seimbang dapat dilakukan dengan mengkonsumsi kacang panjang.

Kacang panjang merupakan tanaman dengan spesies Vigna Sinensis L. Kacang panjang mudah tumbuh dengan baik di berbagai jenis lahan, baik lahan sawah, tegalan bahkan pekarangan rumah dan tidak tergantung musim. Tanaman ini berbentuk perdu, bersifat memanjat dengan membelit, daunnya bersusun tiga-tiga helai, sedangkan bunga kacang panjang seperti kupu-kupu berwarna biru muda, polongnya berwarna hijau berbentuk gilig dengan panjang sekitar 10-80 cm (Kementerian Pertanian, 2013).

Kacang panjang mengandung zat gizi yaitu thiamin pada bagian polong $(0,13 \mathrm{mg})$, biji $(0,57 \mathrm{mg})$ dan daun $(0,28 \mathrm{mg})$ per $100 \mathrm{gr}$ (Haryanto et al, 2007). Thiamin adalah salah satu jenis vitamin B dan merupakan vitamin yang larut dalam air. Zat gizi dalam kacang panjang ini dapat membantu mengendalikan kadar glukosa darah tinggi pada pasien DM. Thiamin mengandung enzim transketolase (Tk), piruvate dehydrogenase dan $\alpha$ ketoglutarate dehydrogenase yang berperan dalam metabolisme glukosa intraseluler melalui peningkatan aktivitas siklus krebs. Kekurangan thiamin menyebabkan kerusakan sintesis dan sekresi insulin (Luong \& Nguyen, 2012), sedangkan tubuh tidak dapat mensintesis thiamin sendiri sehingga memerlukan intake dari luar tubuh, intake yang direkomendasikan 1-1,4 mg per hari (Page el al, 2011).

Thiamin merupakan zat gizi esensial dalam metabolisme karbohidrat. Metabolisme karbohidrat menghasilkan monosakarida yang selanjutnya akan dimetabolisme dan digunakan oleh sel-sel dalam tubuh untuk melakukan aktivitasnya, terutama sebagai sumber energi maupun sebagai sumber pembentukan senyawa lainnya yang diperlukan tubuh untuk dapat berfungsi secara normal (Firani, 2017). Thiamin juga berperan dalam memperbaiki kerja reseptor insulin dan transporter glukosa dalam sel sehingga glukosa dapat bertranslokasi dari membran sel ke intrasel dan kadar glukosa dalam darah dapat teregulasi dengan baik. Glukosa diangkut (ditranspor) ke dalam sel oleh family dari protein transporter khusus yaitu transporter glukosa (glucose transporter, GLUT) (Bilous \& Donelly, 2014). Gonzalez-Ortiz et al (2010) menunjukkan bahwa pemberian suplementasi thiamin $150 \mathrm{mg} /$ hari selama 1 bulan secara signifikan dapat menurunkan 
kadar glukosa puasa pada penderita DM Tipe 2 dengan p-value 0,024, akan tetapi pemberian suplementasi ini tidak signifikan memberikan efek positif terhadap kadar HbA1c.

\section{METODE}

Penelitian ini menggunakan metode quasi eksperiment dengan one group pre-post test design. Pengambilan sampel dilakukan dengan cara purposive sampling. Kadar Glukosa Darah Puasa (GDP) diobservasi/diukur sebelum dan sesudah diberikan jus kacang panjang selama 7 hari. Sampel pada penelitian ini adalah masyarakat yang bertempat tinggal di Dusun Sindet, Desa Wukirsari, Kecamatan Imogiri, Bantul, dengan kriteria inklusi yaitu a) pasien DM Tipe 2 berusia 45-65 tahun, b) kadar GDP 200-350 mg/dl, c) tidak mengkonsumsi obat hiperglikemia oral, dan d) tanpa komplikasi. Masyarakat ini berada dibawah binaan Puskesmas Imogiri. Berdasarkan kriteria inklusi tersebut, jumlah sampel pada penelitian ini adalah 21 orang. Penelitian ini dilakukan pada bulan Februari Tahun 2019.

Tahap awal pengambilan data pada penelitian ini adalah dengan pemeriksaan kadar GDP saat responden datang di puskesmas dan digunakan sebagai data observasi awal (pretest). Kemudian, satu hari selanjutnya, responden diberi jus kacang panjang dua kali sehari, yaitu pagi dan sore hari sebanyak $100 \mathrm{gr} / 50 \mathrm{kgBB}$, tanpa ditambahkan gula maupun air, kemudian dihancurkan dengan menggunakan blender, jus diberikan selama 7 hari. Jus kacang panjang disiapkan oleh peneliti dan diantar ke rumah responden masing-masing. Setelah 7 hari pemberian jus kacang panjang maka pada hari ke-8 akan dilakukan pemeriksaan darah sebagai data observasi akhir (posttest). Analisis data dilakukan menggunaan uji paired $\mathrm{t}$ test dengan tingkat kemaknaan $\alpha \leq$ 0,05 .

Pada penelitian ini, variabel independen yaitu jus kacang panjang, sedangkan variable dependen yaitu kadar glukosa darah pada pasien DM Tipe 2. Instrumen pengumpulan data dengan menggunakan lembar observasi pada pemberian jus kacang panjang dan kadar glukosa darah. Alat yang digunakan untuk mengetahui kadar glukosa darah responden adalah glukostik dari OneTouch Select Simple.

\section{HASIL}

Berdasarkan analisis univariat pada penelitian ini, angka kejadian DM Tipe 2 lebih tinggi pada perempuan dibandingkan laki-laki, yaitu 17 orang $(80,1 \%)$, sedangkan 
usia 55-64 tahun merupakan kelompok usia terbanyak penderita DM Tipe 2 .

Tabel 1. Karakteristik Responden ( $\mathbf{N}=\mathbf{2 1})$

\begin{tabular}{llcc}
\hline \multicolumn{1}{c}{ Karakteristik Responden } & $\mathbf{N}$ & $\mathbf{\%}$ \\
\hline Usia & $25-34$ tahun & 3 & 14,2 \\
\cline { 2 - 4 } & $35-44$ tahun & 5 & 23,8 \\
\cline { 2 - 4 } & 45-54 tahun & 6 & 28,5 \\
\cline { 2 - 4 } & $55-64$ tahun & 7 & 33,5 \\
\hline Jenis & Laki-laki & 4 & 19,9 \\
\cline { 2 - 4 } Kelamin & Perempuan & 17 & 80,1 \\
\hline
\end{tabular}

Sumber: Data Primer 2019

Hasil penelitian ini menunjukkan rerata kadar GDP responden saat pretest $291 \mathrm{mg} / \mathrm{dl}$ dan saat posttest $100 \mathrm{mg} / \mathrm{dl}$, terjadi rerata penurunan kadar GDP $91 \mathrm{mg} / \mathrm{dl}$ setelah pemberian jus kacang panjang selama 7 hari.

Tabel 2. Rerata Kadar GDP sebelum dan sesudah Pemberian Jus Kacang Panjang

\begin{tabular}{lccc}
\hline \multicolumn{1}{c}{ Variabel } & Mean & SD & $\begin{array}{c}\text { p- } \\
\text { value }\end{array}$ \\
\cline { 1 - 2 } $\begin{array}{l}\text { Kadar GDP } \\
\text { sebelum } \\
\text { perlakuan }\end{array}$ & 291,29 & 40,308 & 0,000 \\
\cline { 1 - 1 } $\begin{array}{l}\text { Kadar GDP } \\
\text { setelah } \\
\text { perlakuan }\end{array}$ & 100,90 & 10,535 & \\
\hline
\end{tabular}

Sumber: Data Primer, 2019

Uji statistik menggunakan paired $t$ test menunjukkan nilai signifikan p 0,000 (p < 0,005), diartikan bahwa terdapat perbedaan yang signifikan antara kadar GDP sebelum dan sesudah minum jus kacang panjang. Pemberian jus kacang panjang selama 7 hari berpengaruh secara signifikan menurunkan kadar GDP pada responden.
Tabel 3. Kadar GDP Responden sebelum (pretest) dan sesudah Pemberian Jus Kacang Panjang (posttest) selama 7 hari $(\mathrm{N}=21)$

\begin{tabular}{|c|c|c|c|}
\hline \multirow[b]{2}{*}{ No } & \multicolumn{2}{|c|}{ Perlakuan } & \multirow[t]{2}{*}{ Selisih $(\mathrm{mg} / \mathrm{dl})$} \\
\hline & $\begin{array}{l}\text { Pretest } \\
(\mathrm{mg} / \mathrm{dl})\end{array}$ & $\begin{array}{l}\text { Posttest } \\
\text { (mg/dl) }\end{array}$ & \\
\hline 1 & 221 & 86 & 135 \\
\hline 2 & 250 & 117 & 133 \\
\hline 3 & 310 & 99 & 211 \\
\hline 4 & 319 & 120 & 199 \\
\hline 5 & 290 & 102 & 188 \\
\hline 6 & 275 & 99 & 176 \\
\hline 7 & 216 & 120 & 129 \\
\hline 8 & 240 & 102 & 141 \\
\hline 9 & 340 & 99 & 222 \\
\hline 10 & 345 & 87 & 243 \\
\hline 11 & 330 & 99 & 229 \\
\hline 12 & 290 & 118 & 201 \\
\hline 13 & 315 & 102 & 208 \\
\hline 14 & 320 & 101 & 223 \\
\hline 15 & 330 & 89 & 240 \\
\hline 16 & 310 & 107 & 203 \\
\hline 17 & 310 & 109 & 201 \\
\hline 18 & 300 & 112 & 188 \\
\hline 19 & 290 & 89 & 201 \\
\hline 20 & 216 & 87 & 129 \\
\hline 21 & 300 & 102 & 198 \\
\hline
\end{tabular}

Sumber: Data Primer, 2019

\section{PEMBAHASAN}

Diabetes

Mellitus

(DM)

dikarakteristikkan sebagai gangguan metabolik berupa hiperglikemia (glukosa darah puasa $\geq 126 \mathrm{mg} / \mathrm{dL}$ dan glukosa darah sewaktu $\geq 200 \mathrm{mg} / \mathrm{dL}$ ) kelainan sekresi 
insulin, kerja insulin atau keduanya (Depkes, 2014). Diabetes Mellitus (DM) dikategorikan dalam dua kelompok, yaitu a) Diabetes Mellitus (DM) Tipe 1, terjadi akibat penghancuran autoimun dari sel $\beta$ penghasil insulin di pulau Langerhans pada pankreas (defisiensi absolute), dan b) Diabetes Mellitus (DM) Tipe 2, merupakan dampak dari gangguan sekresi insulin dan resistansi terhadap kerja insulin yang sering kali disebabkan oleh obesitas (defisiensi relatif) (Bilous \& Donelly, 2014). Aklima et al (2013) menjelaskan bahwa perempuan berisiko lebih tinggi menderita DM Tipe 2 daripada laki-laki, hal ini selaras dengan hasil penelitian ini bahwa penderita DM Tipe 2 lebih banyak pada perempuan yaitu 17 orang (80,1\%) dibanding laki laki. WHO (2016) juga menyatakan hal yang sama, bahwa penderita DM Tipe 2 di Indonesia lebih tinggi terjadi pada perempuan $(7,3 \%)$ daripada lakilaki $(6,6 \%)$, dengan faktor risiko kegemukan dan atau obesitas.

DM didiagnosis melalui beberapa pemeriksaan, antara lain: $\mathrm{HbAlc} \geq 6,5 \%$ (48 $\mathrm{mmol} / \mathrm{mol})$, kdar GDS $\geq 11,1 \mathrm{mmol} / \mathrm{L}$ (200 $\mathrm{mg} / \mathrm{dL}$ ) pada individu yang memiliki gejala khas diabetes, kadar GDP $\geq 7,0$ mmol/L (126 $\mathrm{mg} / \mathrm{dL})$, kadar glukosa plasma $\geq 11,1$ $\mathrm{mmol} / \mathrm{L}(200 \mathrm{mg} / \mathrm{dL}) 2$ jam setelah glukosa diberikan sebanyak 75 gr per oral (oral glucose tolerance test, OGTT) (Bilous \& Donelly, 2014). Pada penelitian ini, rerata kadar GDP responden saat pretest $291 \mathrm{mg} / \mathrm{dl}$ dan saat posttest $100 \mathrm{mg} / \mathrm{dl}$, terjadi rerata penurunan kadar GDP $91 \mathrm{mg} / \mathrm{dl}$ setelah pemberian jus kacang panjang selama 7 hari.

Uji statistik menggunakan paired t test menunjukkan nilai signifikan p 0,000 (p < 0,005), diartikan bahwa terdapat perbedaan yang signifikan antara kadar GDP sebelum dan sesudah minum jus kacang panjang. Pemberian jus kacang panjang selama 7 hari berpengaruh secara signifikan menurunkan kadar GDP pada responden. Hasil penelitian ini sesuai dengan Gonzalez-Ortiz et al (2010) bahwa pemberian thiamin secara signifikan dapat menurunkan kadar glukosa puasa pada penderita DM Tipe 2. Harmayetty (2014) juga menyebutkan pemberian jus kacang panjang (vigna sinensis L) dapat menurunkan kadar glukosa darah pasien DM Tipe 2, melalui fungsi regulasi glukosa darah oleh thiamin dan serat dalam kacang panjang. Keshri et al (2016) menjelaskan juga bahwa thiamin mempunyai efek antihiperglikemik, pemberian thiamin berefek positif pada regulasi kadar glukosa darah penderita DM Tipe 2, konsumsi thiamin sebanyak 50 $\mathrm{mg} / \mathrm{kgBB}$ per hari dapat menurunkan kadar glukosa darah. Konsumsi thiamin dilakukan 
selama 6 minggu, dan diobservasi setiap minggu atau per 7 hari, menunjukkan kadar glukosa darah per 7 hari mengalami penurunan, dan setelah 6 minggu terjadi penurunan kadar glukosa darah secara signifikan, tanpa memicu timbulnya hipoglikemia.

\section{KESIMPULAN}

Pemberian jus kacang panjang dapat menurunkan kadar Glukosa Darah Puasa (GDP) pada penderita DM Tipe 2, melalui fungsi regulasi kadar glukosa darah oleh thiamin yang terkandung pada kacang panjang.

\section{DAFTAR PUSTAKA}

Aklima., Kritpracha, C., Thaniwattananon, P. 2013. Dietary Behaviors among Patients with Type 2 Diabetes Mellitus in Indonesia. Nurse Media Journal of Nursing. 3(1). p: 499-509

Departemen Kesehatan. 2018. Cegah, Cegah, dan Cegah: Suara Dunia Perangi Diabetes. Dikutip dari: http://www.depkes.go.id/article/view/18 121200001/prevent-prevent-andprevent-the-voice-of-the-world-fightdiabetes.html

Departemen Kesehatan. 2017. Profil Kesehatan Provinsi Daerah Istimewa Yogyakarta Tahun 2017. Dikutip dari: http://www.depkes.go.id/resources/down
load/profil/PROFIL_KES_PROVINSI_2 017/14_DIY_2017.pdf

Departemen Kesehatan. 2014. Tanya-Jawab seputar Diabetes. Dikutip dari: http://p2ptm.kemkes.go.id/uploads/2016/ 11/Tanya-Jawab-Seputar-Diabetes-1.pdf

Luong, K V Q, Nguyen, L T H. 2012. The Impact of Thiamine Treatment in the Diabetes Mellitus. J Clin Med Res. 4(3): 153-160

Harmayetty, Krisnana, Anisa. 2014. Jus Kacang Panjang (Viga Sinensis L.) Menurunkan Kadar Glukosa Darah Pasien Diabetes Mellitus. Jurnal Ners. Vol.4. No.2. p: 116-121

Kehsri, U PDK, Loc, B P, Choudhury, S. 2016. Effect of Thiamine on Fasting Blood Glucose Level of Non-Diabetic and Diabetic Albino Rats. Sch. Bull. Vol.2. Iss-6A. p: 375-379

Firani, N K. 2017. Metabolisme Karbohidrat. Tinjauan Biokimia dan Patologis. UB Press: $1-5$

Gonzales-Ortiz, M, Matinez-Abundis, E, Robles-Cervantes, Ramirez-Ramirez, V, Ramos-Zavala, MG. 2011. Effect of thiamine administration on metabolic profile, cytokines and inflammatory markers in drug-naïve patients with type 2 diabetes. European Journal of Nutrition. Vol.50. Issue 2.p: 145-149

Page, G L J., Laight, D., Cummings, M H. 2011. Thiamine deficiency in diabetes 
Edudharma Journal, Vol 3 No 2, September 2019, page 1-8

mellitus and the impact of thiamine replacement on glucose metabolism and vascular disease. J Clin Pract. 65(6). p: 684-690

WHO. 2016. Indonesia. Diabetes Country Profiles. Dikutip dari: https://www.who.int/diabetes/countryprofiles/idn_en.pdf

Haryanto, E., Suhartini, T., Rahayu, E. 2007. Budi Daya Kacang Panjang. Swadaya. 511 